\title{
INCREASE IN ACh RELEASE FROM THE RAT BRAIN CORTEX SLICES BY 3',5'CYCLIC ADENOSINE MONOPHOSPHATE
}

\author{
Shoji KATSUKI*, Tomohiro MATSUDA, Fumiaki HATA \\ and Hiroshi YOSHIDA \\ Department of Pharmacology I, Osaka University, \\ School of Medicine, Kita-ku, Osaka 530, Japan \\ Accepted October 4, 1976
}

It is known that activities of adenylate cyclase and cyclic nucleotide phosphodiesterase are higher in brain tissue than in other tissues (1-3), and regulatory roles of $3^{\prime}, 5^{\prime}$-cyclic adenosine monophosphate (cyclic AMP) on brain function have been reported by several workers (4-11). On the other hand, it has becn obscrved that secretion of many kinds of hormones (12-17) and enzymes $(18,19)$ is stimulated by intraccllular cyclic AMP, and such is known to be stored in subcellular granules. Acctylcholine (ACh) is also known to be stored in granules, the so-called synaptic vesicles in the nerve endings (20), and released by nerve stimulation. Accordingly, it is considered that release of ACh may be stimulated by cyclic AMP. The assumption has been supported (21-24) or questioned (25-27) by electrophysiological experiments done on the neuromuscular junction or guinea pig ileum. We carried out studies on brain cortex slices by estimation of the amount of $\mathrm{ACh}$ released into the medium.

Adult healthy Sprague Dawley rats were decapitated and the brains were immediately removed. The cortex slices were then prepared using a Stadie-Rigg's slicer and were weighed on a torsion balance. About $80 \mathrm{mg}$ of the brain cortex slices was incubated with shaking in $2 \mathrm{ml}$ of Ringer's solution containing $127.2 \mathrm{mM} \mathrm{NaCl}, 5.13 \mathrm{mM} \mathrm{KCl}, 2.75 \mathrm{mM} \mathrm{CaCl}_{2}$, $1.28 \mathrm{mM} \mathrm{MgSO}_{4}, 2.5 \mathrm{mM} \mathrm{Na}_{2} \mathrm{HPO}_{4}-\mathrm{HCl}$ buffer $(\mathrm{pH} 7.4), 19.25 \mathrm{mM}$ Tris-HCl buffer $(\mathrm{pH}$ 7.4), $10 \mathrm{mM}$ glucose and $0.05 \mathrm{mM}$ eserine sulfate. After obtaining a steady state by preincubation of the slices for $15 \mathrm{~min}$ at $37^{\circ} \mathrm{C}$, the medium was changed and the slices were then incubated for $15 \mathrm{~min}$ with or without effectors. The amount of ACh released into the medium during incubation for 15 min was cstimated with eserinzed abdominal muscle of Rana Papiens according to the method of Chang and Gaddum (28). Dibutyryl cyclic AMP, norepinephrinc, theophylline or histamine, all had no significant effect on contraction of the frog abdominal muscle by $\mathrm{ACh}$ under our conditions, but $35 \mathrm{mM} \mathrm{KCl}$ did cause a contraction of the muscle as is generally known. Thus, the amount of $\mathrm{ACh}$ in the high $\mathrm{K}^{+}$ medium was estimated by comparison with known concentrations of ACh in frog Ringer's containing $11.7 \mathrm{mM} \mathrm{KCl}$ after dilution of the experimental materials with 2 volumes of K-free frog Ringer's solution.

As shown in Table 1 Exp. A, amount of ACh released from the rat brain cortex slices

* Present address; Research Laboratories, Fujisawa Pharmaceutical Company, Yodogawa-ku, Osaka 532, Japan 
TABl.F 1 Elfects of dibutyryl cyclic AMF and biogenic amines on ACh release from the rat brain cortex slices

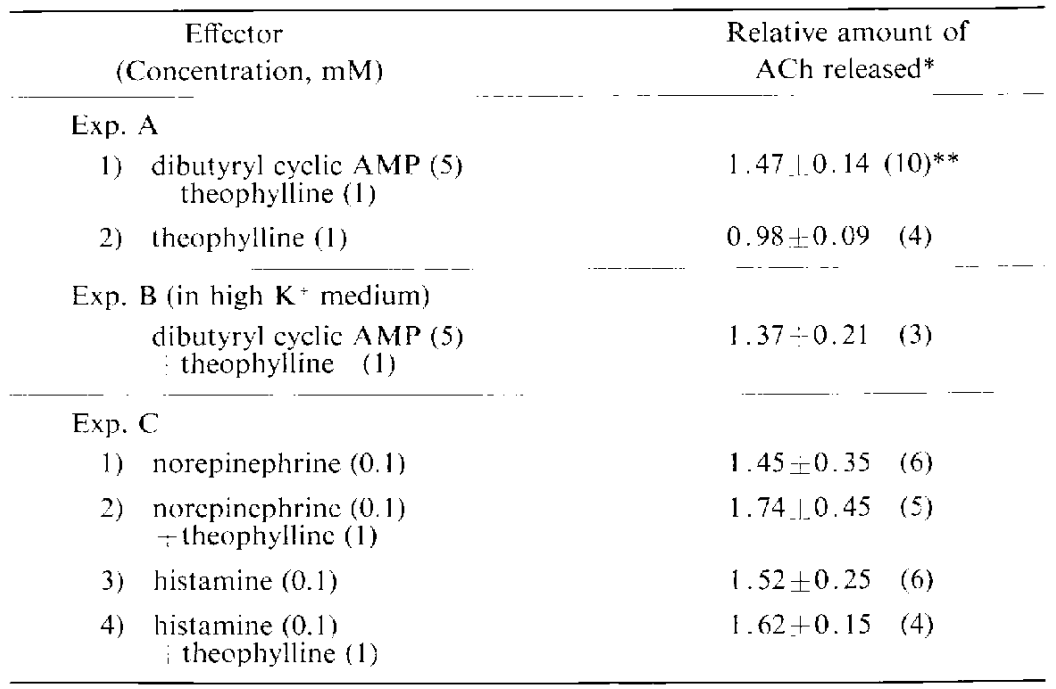

\footnotetext{
* Absolute amount of $\mathrm{ACh}$ released in basic medium was $3.2 \div 0.2(10)$ memolesig slice and this value was taken as 1.0 . ** Mean value - standard deviation (numbers of experiments) In experiment $\mathrm{B}, \mathrm{K}^{+}$concentration in medium was $35 \mathrm{mM}$ and amount of ACh released in this medium without effector was $9.1 \therefore 2.4(7 ; \mathrm{m} /$ moles;g slice. This value was taken as 1.0 in this experiment.
}

was increased by addition of $5 \mathrm{mM}$ dibutyryl cyclic AMP and $1 \mathrm{mM}$ theophylline, though theophylline did not increase the ACh release. Dibutyryl cyclic AMP alone also showed a stimulatory effect on the $\mathrm{ACh}$ release, but the effect seemed to be variable. Miyamoto and Breckenridge (23) reported that stimulatory effect of dibutyryl cyclic AMP on neuromuscular transmission was only observed in preparations exposed to a high $\mathrm{K}^{+}$medium. Accordingly, effect of dibutyryl cyclic AMP on the slices immersed in high $\mathrm{K}^{+}$medium was examined. As shown in Table 1 Exp. B, stimulatory effect of dibutyryl cyclic AMP was observed also in the depolarized state, but its effect was not strengthened by a high $\mathrm{K}^{+}$ medium. Dibutyryl cyclic AMP which is permeable to cell plasma membrane and hardly hydrolyzed by cyclic nucleotide phosphodiesterase (29) has often been used to illustrate action of cyclic AMP inside the cell. Another method of the examination is application of drugs such as norepinephrine and histamine which are known to elevate the level of endogenous cyclic AMP by stimulation of adenylate cyclase activity. Therefore, effects of norepinephrine and histamine on release of ACh from the brain cortex slices were also investigated. These amines increased the ACh release and theophylline showed a tendency to augment the effects of the amines. (Table 1, Exp. C).

These experimental results support the postulation that cyclic AMP may increase ACh release from the nerve endings of the central nervous system in a mannor similar to the release from motor nerve endings. Whether the active site of cyclic AMP is directly on the release process or on the synthesis and storage process of ACh as postulated by Wilson (24), re- 
mains to be clarified.

\title{
REFERENCES
}

1) Sutherland, E.W., Rall, T.W. and Menon, T.: I. biol. Chem. 237, $1220(1962)$; 2) DrumMond, G.I. And Perrott-Yee, S.: J. biol. Chem. 236, 1126 (196i); 3) Butcher, R.W. AND Sutherland, E.W.: J. biol. Chem. 237, 1244 (1962); 4) Gfssa, G.L., Krishna, G., Forn, J., Taglamonte, A. AND Brodi:, B.B.: Adv. Biochem. Prychopharmacol. 3, 371 (1970); 5) Asakawa, T. And Yoshida, H.: Japan. J. Pharmacol. 21, 569 (1971); 6) Purpura, D.P. AND Shofer, R.J.: Brain Res. 38, 179 (1972); 7) Shashoua, V.E.: Proc. natn. Acad. Sci. U.S.A. 68, 2835 (1971); 8) Siggins, G.R., Hofrer, B.J. and Bloom, F.E.: Science 165, 1018 (1971); 9) Siggivs, G.R., Hoffer, B.J. nNo Bloom, F.E.: Science 165, 1069 (1971); 10) Siggins, G.R., Hofjer, B.J. ANd Bloom, F.E.: Brain Res. 25, 535 (1971); 11 ) Siggins, G.R., Oliver, A.P., Hoffer, B.J. and Bloom, F.E.: Sichee 171, 192 (1971); 12) Peach, M.J.: Proc. natr. Acad. Sci. U.S.A. 69, 834 (1972): 13) Fleischer, N., Donal.d, R.A. and Butcher, R.W.: Am. $J$. Physiol. 217, 1287 (1969); 14) WII.BFR, J.F., PEAKF, G.T. AND UTIGER, R.D.: Endocrinol. 84, 758 (1969): 15) MacLiod, R.M. AND LehMeyer, J.E.: Pror. natn. Acad. Sci. U.S.A, 67, 1172 (1970); 16) Lemay, A. ANd LABrif, F.: FEBS Letters 20, 7 (1972); 17) Brisson, G.R., Malaisse-Lagae, F. And Mai aissi, W.J.: J. clin. Inlest. 51, 232 (1972); 18) Bdolait, A. And Schram, M.: Biochem. biophys. Res. Commun. 18, 452 (1965); 19) Malamud, D.: Biochim. Biophys. Acta 279, 373 (1972); 20) Whittaker, V.P., Michafl.son, I.A. ANd Kirkland, R.J.A.: Biochem. J. 90, 293 (1964): 21) BrtckENRIDGE, B. MCL., BURN, J.H. AND MATSCHINSKY, F.M.: Proc. nath. Acad. Sci. U.S.A. 57, 1893 (1967); 22) Goldrerg, A.L. And Sixger, J.J.: Proc. natn. Acad. Sci. U.S.A. 64, 134 (1969); 23) Miyamoto, M.D. AxD BrLckenridge, B.MCL.: J. gen. Physiol. 63, 609 (1974): 24) WILson, D.F.: J. Pharmacol. exp. Ther. 188, 447 (1974); 25) Quastel, D.M.J. Ano Hackell, J.T.: Fed Proc. 30, 557 (1971); 26) Ginsborg, B.L. and Hirst, G.D.S.: J. Physiol. 224, 629 (1972); 27) Takngi, K. avd Takayanagi, I.: Jupan. J. Pharmacol. 22, 36 (1972); 28) CHANG, H.C. AND GaDdum, J.H.: J. Physiol. 79, 255 (1933); 29) Posternak, T. ANo Sutherland, E.W.: Biochim. Biophys. Acta 65, 558 (I962)

\section{EFFECT OF VERAPAMIL ON FREQUENCY-FORCE RELATIONSHIP IN ISOLATED DOG LEFT VENTRICULAR MUSCLE}

\author{
Shigetoshi CHIBA \\ Department of Pharmacology, Faculty of Medicine, \\ Shinshu University, Matsumoto 390, Japan
}

Accepted October 6, 1976

In 1970, Endoh and Hashimoto (1) developed the canine papillary muscle preparation of the right ventricle perfused with blood for the studies on physiological and pharmacological properties of the myocardium. In the present study, part of left ventricular muscle was perfused with blood and effect of vcrapamil on the frequency-force relationship was investigated. The differences between the papillary muscle preparation and the isolated left ventricular muscle are as follows: 1) In the present study, the left ventricular muscle was used, while in the papillary muscle preparation, the right ventricular muscle was used. 2) In this study, the muscle was bathed in the container filled with blood, however in the papillary muscle preparation, the muscle was covered with betl-shaped glass containers which 